\title{
CASE 1-2011: SMALL INTESTINAL DIFFUSE LARGE B-CELL LYMPHOMA IN A 58-YEAR-OLD PATIENT WITH COELIAC DISEASE
}

\author{
Paula Sopirjaková1, Miroslav Podhola², Marcela Kopáčová1, Ilja Tachecí1, Milan Hlista ${ }^{3}$, Jolana Bártová1, \\ Stanislav Rejchrt ${ }^{1}$, Jan Bureš ${ }^{1}$
}

Charles University in Prague, Faculty of Medicine and University Hospital Hradec Králové, Czech Republic: $2^{\text {nd }}$ Department of Medicine \& University Department of Gastroenterology ${ }^{1}$, The Fingerland Department of Pathology ${ }^{2}$ Centre of $^{2}$ Gastroenterology, Department of Internal Medicine, Teaching Hospital, Trenčín, Slovakia ${ }^{3}$

\section{Introduction}

Coeliac disease is an inflammatory disease of the small intestine induced by gluten in genetically predisposed persons which can result in intestinal mucosal atrophy and malabsorption with wide spectrum of symptoms (diarrhoea, anaemia, osteoporosis, infertility, neurological disorders etc.). Numerous studies have observed an increase in overall mortality in patients with coeliac disease compared to the general population, except of non-Hodgkin lymphoma. The relative risk for the development of lymphoma is 3-6-fold increased and persisting for five years after diagnosis despite strict adherence to gluten free diet (5). In this case report, authors present a middle-aged man with small intestinal non-Hodgkin lymphoma in previously undiagnosed coeliac disease.

\section{Clinical data}

A 56-year-old man has been examined in a regional hospital in Slovakia since May 2007 for upper abdominal pain occurring 4 hours after meal, sticky stools, weight loss of $10 \mathrm{~kg}$ and mild anaemia (haemoglobin $120 \mathrm{~g} / \mathrm{L}$ ). Till that time he felt fit, he did not receive any medical treatment. There was no cancer or coeliac disease in his family history. Abdominal ultrasonography did not reveal any pathology. At upper gastrointestinal endoscopy there was mild villous atrophy of the duodenal mucosa and suspicious coeliac disease was confirmed by biopsies (type $3 \mathrm{~b}$ according to Marsh-Oberr classification at histology). Serologic markers were positive for coeliac disease (IgA anti-human tissue transglutaminase $31.2 \mathrm{U} / \mathrm{L}$; IgA and IgG antigliadin antibodies positive). The patient started up with gluten free diet with good clinical effect. After one year on diet, most of the symptoms disappeared, and also upper endoscopy with biopsy confirmed remission of coeliac disease. Nevertheless, pain in the upper abdomen evolving 4 hours after meals persisted. CT of the abdomen found enlargement of a part of the ileum with regional lymphadenopathy. There was elevated serum beta2-microglobulin $(4.6 \mathrm{mg} / \mathrm{L})$. These findings raised suspicion of some complication of the coeliac disease. In February 2009, the patient was re-admitted for further weight loss and persisting abdominal pain. Laboratory examinations found normal haemoglobin, total protein and albumin. Normalization of the $\operatorname{IgA}$ antihuman tissue transglutaminase proved good adherence to gluten free diet. Upper GI endoscopy showed mild atrophy of the duodenal mucosa, a search for Giardia lamblia in duodenal juice was negative. Magnetic resonance affirmed enlargement of a part of the ileum and enlarged regional lymph nodes. Wireless capsule endoscopy showed atrophy of the small intestinal mucosa, ulcers and ileal stenosis. Colonoscopy with intubation of terminal ileum did not reach the affected part of the ileum. The patient started treatment with topical steroids and pancreatic enzymes and he gained his weight to normal.

In November 2009, the patient was referred to our Department for double balloon enteroscopy. On admission, he complained of persisting abdominal pain 4 hours after the meal. There was no palpable lymphadenopathy or abdominal mass. Double balloon enteroscopy showed multiple ulcers in proximal part of the ileum during deep enteroscopy. The length of the affected intestine was about $30 \mathrm{~cm}$. Histology of multiple biopsy specimens revealed diffuse large B-cell lymphoma. Sternal bone marrow aspirate smear and histology did not find infiltration by lymphoma. Stage IIA lymphoma was set according to the Ann Arbor staging system. The patient was treated by chemotherapy with the R-CHOP regimen (rituximab, cyclophosphamide, doxorubicin, vincristine and prednisone). Full clinical remission was achieved and the patient has been symptom free for 12 months. 


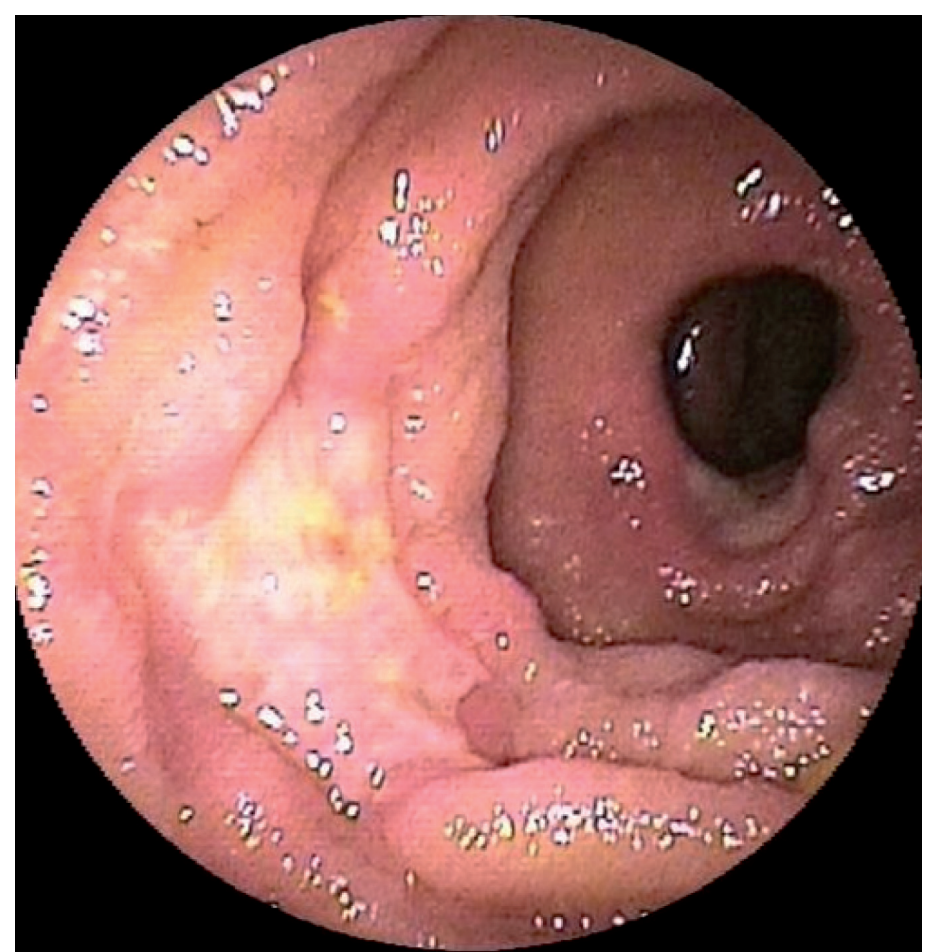

Fig. 1: Double balloon enteroscopy, view of the proximal ileum. Multiple ulcers and obvious infiltration of surrounding intestinal mucosa by lymphoma.
Tab. 1: Distribution of lymphoma subtypes in coeliac disease according to the WHO classification (7).

\begin{tabular}{|c|c|}
\hline $\begin{array}{l}\text { Lymphoma } \\
\text { subtype }\end{array}$ & $\begin{array}{c}\text { No. of } \\
\text { patients } \\
(\mathrm{n}=56)\end{array}$ \\
\hline Mature B cell neoplasms & \\
\hline Diffuse large B cell lymphoma & 7 \\
\hline Follicular lymphoma & 3 \\
\hline $\begin{array}{l}\text { Extranodal marginal zone B cell } \\
\text { lymphoma of MALT }\end{array}$ & 2 \\
\hline Mantle cell lymphoma & 2 \\
\hline Unspecified low grade B cell lymphoma & 1 \\
\hline Unspecified B cell lymphoma & 1 \\
\hline Mature T cell and NK cell neoplasms & \\
\hline Enteropathy-type T cell lymphoma & 19 \\
\hline Anaplastic large cell lymphoma & 6 \\
\hline Peripheral $\mathrm{T}$ cell lymphoma, unspecified & 10 \\
\hline $\begin{array}{l}\text { Extranodal NK/T cell lymphoma, nasal } \\
\text { type }\end{array}$ & 1 \\
\hline $\begin{array}{l}\text { Subcutaneous panniculitis-like T cell } \\
\text { lymphoma }\end{array}$ & 1 \\
\hline Hodgkin lymphoma & \\
\hline $\begin{array}{l}\text { Mixed cellularity classical Hodgkin } \\
\text { lymphoma }\end{array}$ & 1 \\
\hline Unspecified lymphomas & \\
\hline Unspecified high grade NHL & 1 \\
\hline Unspecified NHL & 1 \\
\hline
\end{tabular}

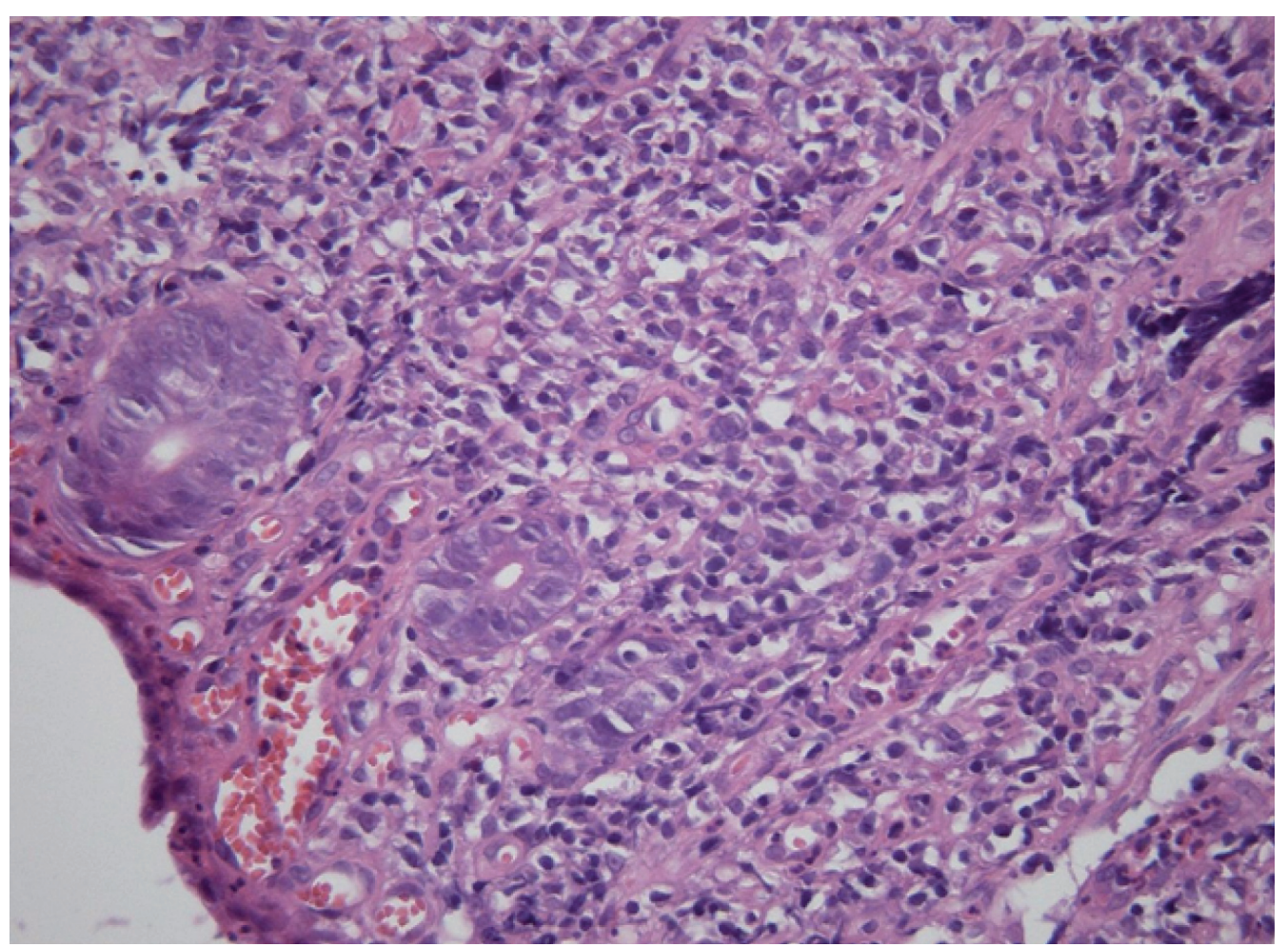

Fig. 2: Histology. Diffuse infiltration of the intestinal mucosa by lymphoma. Hematoxylin-eosin staining. Original magnification 100x. 


\section{Pathology}

The mucosa of small intestine was ulcerated by tumour infiltrate composed exclusively of large cells of a centroblast type. The labelling pattern was CD20+, MUM1+, CD10-, CD5-, AE1/AE3-. A diagnosis of extranodal diffuse large B-cell lymphoma was rendered.

\section{Discussion}

We report an unusual case of large cell B-cell lymphoma in a patient with previously undiagnosed coeliac disease. In this particular case, postprandial abdominal pain, lasting for more that two years, was caused by ileal lymphoma. After coeliac disease was diagnosed, and gluten free diet instituted, the malabsorption was resolved but the pain persisted. The delay in the diagnosis and proper treatment was caused by previous unavailability of deep enteroscopy, not allowing biopsy sampling of the affected small intestinal loops. After the chemotherapy with RCHOP regimen (rituximab, cyclophosphamide, doxorubicin, vincristine and prednisone) full clinical remission was achieved.

The association of coeliac disease and lymphoma was first published in 1962. Since that time, numerous case reports and case series have focused on the relationship between coeliac disease and T-cell lymphoma of the small intestine, which is nowadays, according to the recent WHO classification, assigned as EATL (enteropathy associated T-cell lymphoma). The association of coeliac disease and other types of lymphomas is not clear. The most extensive prospective study published so far monitored incidence of lymphomas in 11,650 patients with coeliac disease in Sweden between 1964-1995 (7). During this period lymphoma was diagnosed in 56 patients $(0.48 \%)$. The observed ratio of T-cell non-Hodgkin lymphomas to B-cell non-Hodgkin lymphomas was surprisingly 7:3. The most frequent T-cell lymphoma was EATL (enteropathy associated T-cell lymphoma), comprising, however, only $30 \%$ of all lymphomas (see Table 1 for details). Primary gastrointestinal origin of lymphomas was comparable to non-intestinal origin. The relative risk for developing lymphoma in untreated coeliac disease is 3-6-fold increased. After strict adherence to gluten free diet for 5 years or more, the risk of lymphoma approaches that of normal population (7). Similar population-based studies on lymphoma in coeliac disease were run also in Finland (9), the United Kingdom (1), and the Netherlands (8).

The mechanism of developing lymphoma in coeliac disease is well described in EATL, and it is related to refractory coeliac disease (type I and II) that is defined by persistent symptoms of malabsorbtion and intestinal villous atrophy despite strict gluten free diet. Refractory coeliac disease can develop in $5-10 \%$ of patients. It is considered to be "a window to lymphoma" (4). Refractory coeliac disease is classified into 2 types based on the immunophenotype of intraepithelial T-lymphocytes: type I with phenotypically normal intraepithelial T-lymphocytes and type II with aberrant intraepithelial $\mathrm{T}$ cell population with lack of expression of CD4/8, CD3 and rearrangement of T-cell receptor $\gamma / \delta$. Clonal expansion of aberrant lymphocytes progresses into EATL. Fifty per cent of patients with refractory coeliac disease type II would progress into EATL within 5 years after the diagnosis. The pathogenesis of non-intestinal Tcell lymphomas assumes the same mechanism with disseminating of aberrant monoclonal lymphocytes into the blood circulation. The pathways involved in B-cell lymphomas are not fully recognized, yet they seem to be related to chronic inflammation and autoimmune character of the disease $(2,3,6)$.

Non-Hodgkin lymphoma is a rare complication of coeliac disease. However, this possibility should be always considered in patients with persisting symptoms, independently on adherence to gluten free diet. The predominant types of lymphoma in coeliac disease comprise T-cell nonHodgkin lymphomas, but B-cell lymphoma is also possible, as documented by our case report.

\section{Message from Editor (prof. Šteiner)}

The presented case of coeliac disease (gluten - sensitive enteropathy) appears remarkable from two points of view presentation of celiac disease in late adulthood, and association with lymphoma.

Although coeliac disease is generally viewed as a disorder of infancy and childhood, it may not infrequently present in mid-adulthood (30-40 years), or even later, as documented by our case.

Removal of gluten from the diet is met with dramatic improvement of the malabsorption symptoms. There is, however, a low long-term risk of malignant disease, with about a twofold increase over the usual rate. Intestinal lymphomas are disproportionally represented; other malignancies include gastrointestinal and breast carcinomas. In some patients with coeliac disease there is an associated skin disorder - dermatitis herpetiformis.

\section{Acknowledgement}

This study was supported by research project MZO 00179906 from the Ministry of Health, Czech Republic.

\section{References}

1. Anderson LA, McMillan SA, Watson RG, et al. Malignancy and mortality in a population-based cohort of patients with coeliac disease or "gluten sensitivity“. World J Gastroenterol 2007; 13: 146-151.

2. Howdle PD, Jalal PK, Holmes GKT, Houlston RS. Primary small-bowel malignancy in the UK and its association with celiac disease. Q J Med 2003; 96: 345-353.

3. Malamut G, Afchain P, Verkarre V, et al. Presentation and long-term follow up of refractory celiac disease: comparison of type I with type II. Gastroenterology 2009; 136: 81-90. 
4. Mulder CJ, Wahab PJ, Moshaver B, Meijer JW. Refractory coeliac disease: a window between coeliac disease and enteropathy associated $\mathrm{T}$ cell lymphoma. Scand J Gastroenterol 2000; vol 35, Suppl 232:32-37.

5. Schuppan D, Dietrich W. Pathogenesis, epidemiology, and clinical manifestations of celiac disease in adults. UpToDate on line, 18.3. Wellesley, 2010. Available from http://www.uptodate.com.

6. Schuppan D, Junker Y, Barisani D. Celiac disease: from pathogenesis to novel therapies. Gastroenterology 2009; 137: 1912-1933.

7. Smedby KE, Akerman M, Hildebrand $\mathrm{H}$, et al. Malignant lymphomas in celiac di- sease: evidence of increased risks for lymphoma types other than enteropathytype T cell lymphoma. Gut 2005; 54: 54-59.

8. Verbeek WH, Van De Water JM, Al-Toma A, et al. Incidence of enteropathy-associated T-cell lymphoma: a nation-wide study of a population-based registry in The Netherlands. Scand J Gastroenterol 2008; 43: 1322-1328.

9. Viljamaa M, Kaukinen K, Pukkala E, et al. Malignancies and mortality in patients with coeliac disease and dermatitis herpetiformis: 30-year population-based study. Dig Liver Dis 2006; 38: 374-380.

\section{Corresponding author:}

Paula Sopirjaková, MD, $2^{\text {nd }}$ Department of Medicine, University Hospital, Sokolská 581, 50005 Hradec Králové, Czech Republic; e-mail: sopirpau@fnhk.cz 